DOSSIÊ TEMÁTICO: Vitalidade do sujeito e poder de formação: narrativas autobiográficas em diálogo

\title{
APRESENTAÇÃO DO DOSSIÊ TEMÁTICO VITALIDADE DO SUJEITO E PODER DE FORMAÇÃO: NARRATIVAS AUTOBIOGRÁFICAS EM DIÁLOGO
}

\author{
PRESENTATION OF THE THEMATIC DOSSIER Subject vitality and training power: \\ autobiographical narratives in dialogue
}

PRESENTACIÓN DEL DOSSIER TEMÁTICO Vitalidad del sujeto y poder formativo: narrativas autobiográficas en diálogo

PRÉSENTATION DU DOSSIER THÉMATIQUE Vitalité du sujet et pouvoir d'entraînement: récits autobiographiques en dialogue

Elizeu Clementino de Souza Universidade do Estado da Bahia - Brasil

Hervé Breton

Université de Tours - França

Daniel Hugo Suárez

Universidade de Buenos Aires - Argentina

As narrativas de si e as histórias de vida têm um poder de engajar o sujeito, através da passagem da experiência à linguagem, em um trabalho de elaboração, diálogo e releitura da sua experiência. Esta atividade narrativa emerge de uma dinâmica de "antropoformação" que começa e se desdobra a partir das forças vitais do sujeito. Esta perspectiva hermenêutica de formação mobiliza a expressão em primeira pessoa e envolve o sujeito nas formas de narração que este dossiê propõe-se examinar: passagem da experiência à linguagem; processos de expressão narrativa; circulação dos registros de expressão; releitura coletiva da experiência vivida; temporalidades dos efeitos da narrativa; transformação das perspectivas de existência. O objetivo deste dossiê é caracterizar as práticas narrativas, formalizar seus procedimentos, especificar os tipos de efeitos sobre a dinâmica da autoformação. Trata-se também de refletir sobre a contribuição específica e singular do trabalho narrativo para a restituição do poder de formação contido nas forças vitais do sujeito: processo de individuação; trabalho de singularização; dinâmica de emancipação. Assim, se a autobiografia pode ser considerada como 
um dispositivo fundador da dinâmica da autoformação, as formas tomadas pelas narrativas de si podem ser questionadas de acordo com diferentes práticas (individual/coletiva; oral/escrita...) e em diferentes contextos (educação, trabalho, saúde, movimentos sociais...).

Esses primeiros elementos, que postulam uma reciprocidade entre a expressão em palavras da experiência e os processos formativos vividos pelo sujeito durante o trabalho narrativo, trazem para pesquisadores, formadores e professores uma forma de exigência que consiste em procurar caracterizar e compreender de forma qualitativa e temporal a dinâmica formativa gerada pela atividade narrativa. Neste dossiê, a caracterização dos processos de formação é ancorada na noção de vitalidade. Isso nos leva a afirmar uma concepção do que é um processo de formação e, em particular, diferenciá-lo de abordagens instrumentais ou puramente operacionais que reduzem o aprendizado a estratégias para adaptar o conteúdo da formação ao seu ambiente. Pensar na formação do ponto de vista da vitalidade possibilita-nos aproximações e diálogos com correntes e tradições da hermenêutica, especialmente das "ciências do espírito" (DILTHEY, 1910/1988). Narrar a própria experiência pressupõe entender-se como uma entidade viva e em evolução no mundo, imersa em coletivos e comunidades, em espaços sociais e ambientes ecológicos. De acordo com essa perspectiva, a narrativa de si é acompanhada de processos de compreensão que se dão através da reflexividade e da historicidade. Ests ponto é precípuo pois oferece uma primeira base para pensar sobre o poder formativo gerado pela atividade biográfica e (auto)biográfica.

Entretanto, a noção de vitalidade precisa ser esclarecida. Várias direções podem ser tomadas para isso. A primeira seria, por exemplo, apresentar a ideia de que a formação procede de um movimento antropológico pelo qual o sujeito constrói sua experiência através das diferentes formas e tipos de narrativa. Segundo essa perspectiva, o poder da formação resulta de uma força inscrita nas capacidades do sujeito, sua atualização pressupõe uma forma de incitação e alimentação que resulta da imersão no mundo da vida (SCHÜTZ, 1943/1987), de uma forma simultaneamente implicada e reflexiva. Esta perspectiva, de acordo com as teorias de formação de Bildung e Lebensphilosophie, não é a única. Uma segunda direção, não necessariamente competitiva, insiste na parte da agentividade do sujeito no trabalho de construção de si. Isso nos leva a estar atento às funções de apoio da narrativa que tornam possível apoiar, encorajar ou simplesmente remover os obstáculos que participam do desenvolvimento de uma ação singular através da qual o sujeito pode desenvolver seu estilo e afirmar seus valores no curso das ações que empreende. De acordo com certos aspectos, a dinâmica aqui em questão diz respeito à emancipação: reapropriação do próprio poder formativo (PINEAU et MARIE-MICHÈLE, 1983), emancipação das formas de relação aos 
chamados conhecimentos externos inculcados pelo mundo escolar (ILLICH, 1980), ampliação do escopo de reconhecimento dos saberes do sujeito e dos coletivos (BOAVENTURA DE SOUZA, 2016).

Uma terceira perspectiva também é possível. É mais radical e está orientada para um continente muitas vezes despercebido e ausente dos sistemas de formação. Trata-se da experiência do corpo, dos saberes incorporados, daquilo que compõe uma experiência realizada em ambientes ecológicos e cujas relações participativas são regidas pelo tácito, pelo sensível e pela infra-linguagem. Quando então a noção de vitalidade é invocada, trata-se da energia que circula nas transações do sujeito com o seu ambiente, com as suas equipes de trabalho e com o mundo da vida. Pensar na formação das forças do corpo é integrar as esferas do corpóreo (MERLEAU-PONTY, 1976), do ecológico e do sensível (LAPLANTINE, 2020) a fim de se interessar pelos fenômenos discretos e difusos que configuram os ambientes, mediante os modos de participação do sujeito, sejam eles sociais, materiais, culturais ou naturais. Essas dimensões estão muitas vezes ausentes das narrativas (auto)biográficas. Por serem muito singulares, muito discretas, muito ambientais, são difíceis de entender e de descrever. Muito frequentemente, o vocabulário não está disponível, as palavras dizem muito pouco, muito longe, muito grosseiramente. Existe então o risco de distorcer o poder da experiência (FERRY, 1991) ao escorregar, devido à falta de capacidade narrativa, da narrativa em primeira pessoa dos males típicos e declarativos "em terceira pessoa". Isto faz com que o esforço narrativo seja ainda mais exigente. Os desafios são três: caracterizar as práticas narrativas que contribuem para o acesso à vida sensível, a fim de integrar essas esferas de experiência nas histórias de vida; formalizar métodos que se destinam à expressão em palavras da experiência vivida, dando direito tanto ao sensível quanto ao social; consolidar o paradigma da formação experiencial, reafirmando os processos de reciprocidade entre autobiografia e autoformação.

Os artigos deste dossiê apresentarão pesquisas que permitem questionar e examinar a dinâmica e os efeitos da narrativa sobre a formação do tema a partir dessas perspectivas, especificando suas âncoras teóricas, especificando os contextos de pesquisa, caracterizando os resultados gerados e traduzindo-os em termos epistemológicos e políticos.

O texto "Diante do espelho em tempos de pandemia, em cinco atos", de Gabriel Jaime Murillo-Arango da Universidad de Antioquia - Colômbia, centra-se em reflexões autobiográficas do autor diante da experiência com a pandemia, entrecruzando leituras e diálogos com autores e testemunhos coletados em processos de conversações nas aulas virtuais, atentando-se para além das palavras, não ditos, silêncios e formas de acolhimento no contexto do isolamento social. 
O artigo "A narração da experiência vivida face ao "difícil problema" da experiência: entre memória passiva e historicidade" (La narration du vécu à l'épreuve du "problème difficile » de l'expérience: entre mémoire passive et historicité), de Hervé Breton (Université de Tours-França), questiona processos experienciais relacionados aos microeventos cotidianos na atividade narrativa, dialogando com princípios da hermenêutica, da fenomenologia e da pesquisa biográfica. Destaca-se, assim, potências e fertilidades do trabalho biográfico para dimensões das histórias de vida em formação e da pesquisa biográfica.

Em "Narrativa (auto)biográfica e suas contribuições: da produção do conhecimento à formação dos sujeitos”, Camila Aloisio Alves da Faculdade de Medicina de Petrópolis (FMP) discute questões voltadas para processos relacionados ao narrador e ao pesquisador no domínio da abordagem (auto)biográfica. A análise incide na narrativa de um profissional de saúde, objetivando apontar elementos voltados para a vitalidade do sujeito que a narrativa (auto)biográfica coloca em relevo, especialmente, no que se refere às formas que o vivido ganha com as palavras, mediante reflexões construídas pelo sujeito quando narra sobre suas experiências e dos modos como constrói conhecimento face sua existencialidade no mundo.

O texto "Narrativas autobiográficas e a questão do sujeito: articulações no campo do currículo”, de autoria de Carmen Teresa Gabriel da Universidade Federal do Rio de Janeiro (UFRJ), sistematiza questões teóricas no campo do currículo sobre a potencialidade heurística da articulação entre os estudos autobiográficos e o debate contemporâneo sobre a categoria sujeito no âmbito do quadro de inteligibilidade pós-fundacional. A análise incide sobre pistas investigativas que possibilitam aporias e atravessamentos de reflexões curriculares, ao focalizar reflexões e desafios não binários de apropriações de "sujeito do conhecimento", "sujeito de demandas" e "sujeito do desejo" quando posicionados como docentes e /ou alunos(as) em contextos discursivos específicos. Relações entre processos de subjetivação e "sujeito biográfico" são postas em relevo para sínteses da produção acadêmica dos últimos cinco anos no campo do currículo.

As reflexões apresentadas por Maria da Conceição Passeggi da Universidade Federal do Rio Grande do Norte (UFRN) e Universidade Cidade de São Paulo (Unicid), no texto "Reflexividade narrativa e poder auto(trans)formador", destacam diversidades e modos de uso das abordagens biográficas em educação, ao demarcar o poder transformador da ação de narrar a experiência vivida. Tal processo implica considerar potências da reflexividade narrativa para o sujeito, através de sentidos atribuídos ao ordenamento narrativo dos acontecimentos e da reconstrução de si, mediados pela linguagem. O texto toma como centralidade discussões 
conceituais das noções de autobiografização e de heterobiografização e suas articulações com a reflexividade narrativa e suas implicações para a formação humana.

O texto "Ruralidades esgarçadas e os modos de grafar a escola pelas crianças", de autoria de Mariana Martins de Meireles da Universidade Federal do Recôncavo da Bahia (UFRB) e Elizeu Clementino de Souza da Universidade do Estado da Bahia (UNEB), analisa narrativas de crianças sobre a experiência de habitar Canudos Velho, concentrando-se nos modos como as crianças tecem suas experiências, atribuem sentidos aos lugares e grafam espaços vividos. Discussões sobre ruralidades e modos de habitar o rural são marcadas por processos de exclusão e marginalização social, associados à negação de direitos e à ausência de políticas públicas que assegurem melhores condições de vida para os sujeitos. Daí emerge a ideia problematizada no texto de esgarçamento do rural, situando elementos para pensar o papel do estado e de políticas que atuem para a transformação dessa realidade, da escola e da educação.

Raquel ALS Venera da Universidade Regional de Joinville, no texto "Um trabalho pela vida: narrativa de si contra a coisificação dos corpos", apresenta reflexões teóricas e deslocamentos provocados por narrativas produzidas em contexto de pesquisa e luta pela vida e não coisificação dos corpos, possibilitando pensar condições pelas quais as vidas são submetidas à lógica neoliberal e a reflexões da psicanálise e engendramentos das narrativas nos processos formativos e das narrativas como amálgama dos imaginários fantasmagóricos.

$\mathrm{O}$ artigo "Investigação biográfica e análise com software: cooperação, empoderamento, (des)envolvimento", de Conceição Leal da Costa da Universidade de Évora, João Paulo Oliveira do Instituto Federal de Rio Grande do Norte (UFRN) e Isabel Cavas da Universidade de Évora, discute questões sobre pesquisa biográfica no campo educacional e a utilização do software de análise NVIVO, ressaltando-se relações emergentes e cooperadas construções de sentidos, bem como desafios teórico-metodológicos dos processos de análise de narrativas.

Em "O claro-escuro da transmisão, acompanhamento e formação de professores iniciais”, de autoria de José Antonio Serrano Castañeda da Universidad Pedagógica NacionalAjusco/México, Noemí Hernández Suárez da Universidad Pedagógica NacionalAjusco/México e Juan Mario Ramos Morales da Universidad Pedagógica NacionalAjusco/México, problematiza-se aspectos concernentes à noção de transmissão no processo de acompanhamento de docentes recém-iniciados em ambientes institucionais de ensino superior. Assim, são discutidas questões sobre formação e suas condições objetivas e subjetivas, com ênfase em processo de incorporação e transmissão como efeitos comunicacionais e políticos. A 
noção de claro-escuro da transmissão, ganha centralidade através da análise de dois diários narrativos de professoras construídos no processo de imersão em uma instituição de ensino superior, modos como tornarem-se professores universitários e vicissitudes do acompanhamento na dimensão da formação.

O texto "Vivências iniciais no magistério e formação para a sensibilidade na sala de aula”, escrito por Paula Perin Vicentini da Universidade de São Paulo (USP), Rita de Cassia Gallego da USP, e Rosario Genta Lugli da Universidade Federal de São Paulo da (UNIFESP) e Vivian Batista da Silva também da USP, analisa relatos de quatro professoras iniciantes em exercício da docência que realizaram estágios curriculares diferenciados, na Escola de Aplicação da Faculdade de Educação da USP (EAFEUSP) e no Programa de Residência Pedagógica da Universidade Federal de São Paulo (Unifesp), com formação pela USP e pela Unifesp. A análise empreendida busca compreender dimensões da memória de seus percursos escolares, das experiências vivenciadas durante o estágio e modos como os conteúdos teóricopráticos do curso foram mobilizadas para a elaboração de um repertório inicial de práticas, num momento em que elas estão dando forma às suas auto-imagens como docentes.

Nilton Paulo Ponciano do Instituto Federal de Educação, Ciência e Tecnologia do Amazonas (IFAM) e Augusto José Savedra Lima também do IFAM discutem no texto "Pesquisa-formação e narrativa de si: agentividade e suas dinâmicas figuracionais no sentirse professor de língua portuguesa" dimensões da narrativa e disposições da reflexividade sobre o vivido para a construção de uma representação do sentir-se professor, com base na mediação da consciência-eu/consciência-nós, no estudo da ação narrativa do sujeito sobre o mundo, em um movimento relacional que o indivíduo constrói ao ser no mundo, como construção epistemológica e ontológica.

$\mathrm{O}$ artigo "Formador de adultos: o potencial (trans)formador da biografia", de Carmen Cavaco do Instituto de Educação da Universidade de Lisboa, centra-se na análise do potencial formativo da narrativa autobiográfica no formador de adultos, resultando de uma investigaçãoformação-ação, filiada na hermenêutica, realizada com formadores de adultos, na condição de estudantes de mestrado, em Portugal, destacando o poder de ação e de transformação da narrativa do formador em articulação com percursos profissionais e processos de formação.

Mónica Araújo da Universidade do Minho e Teresa Sarmento da Universidade do Minho no texto "Histórias de vida e formação de cuidadoras de idosos" refletem dimensões teórico-metodológicas das histórias de vida e narrativas de cuidadoras de pessoas da terceira idade. $\mathrm{O}$ escutar as suas vozes constitui, à partida, o reconhecimento pelo valor da sua vida, o que releva a pertinência política das histórias de vida no campo pessoal, bem como da 
investigação enquanto manifestação do entendimento de cada sujeito como participante no processo de construção de conhecimento social.

O texto "Ressonâncias de narrativas autobiográficas na formação continuada de professores", de autoria de Antonia Edna Brito da Universidade Federal do Piauí (UFPI) aborda e analisa narrativas na formação continuada de professores dos anos iniciais do ensino fundamental na perspectiva de analisar suas ressonâncias nos processos de autoconhecimento, de autoformação e de compreensão das condições objetivas e subjetivas dessa formação e da prática docente.

O dossiê é finalizado com o texto "Armazém de momentos: um memorial coletivo elaborado por professoras em formação”, de Ecleide Cunico Furlanetto da Unicid, Helena Aparecida Verderamis Sellani da Unicid e Karina Alves Biasoli dessa mesma instituição, ao centrar-se na análise de um memorial coletivo de formação denominado "Armazém de Momentos", elaborado por sete professoras das séries iniciais do ensino fundamental. Objetivou-se compreender os modos como o trabalho com narrativas, em contexto formativo, poderia potencializar e revelar movimentos individuais e coletivos de formação.

Os textos apresentados no dossiê refletem disposições das narrativas (auto)biográficas em diálogos nacionais e internacionais, concentrando análise sobre a vitalidade dos sujeitos crianças, jovens, adultos, idosos - ou mesmo professores, profissionais de saúde, agentes sociais e modos como através das narrativas revelam o poder da palavra e da formação.

Desejamos que o dossiê possa contribuir com leituras outras e ampliações de diálogos sobre a vitalidade do sujeito e o poder da formação, compreendendo a linguagem e o trabalho de elaboração da experiência em narrativa como uma dinâmica de "antropoformação", como ação de existencialidade do próprio sujeito e dos diálogos com suas histórias, memórias e significados que são construídos de modo singular e plural no contexto do trabalho narrativo.

\section{Referências}

BOAVENTURA DE SOUZA, Santos. Épistémologies du sud. Mouvements citoyens et polémiques sur la science. Paris : Desclée de Brouwer, 2016.

DILTHEY, Wilhem. L'édification du monde historique dans les sciences de l'esprit. Paris : Les éditions du Cerf, [1910]1988.

ILLICH, Ivan. Une société sans école. Paris: Seuil, 1980.

Ferry, Jean-Marc. Les grammaires de l'expérience. Paris : Les éditions du Cerf, 1991. LAPLANTINE, François. Le social et le sensible. Introduction à une anthropologie modale. Paris : Téraèdre, 2020.

MERLEAU-PONTY, Maurice. Phénoménologie de la perception. Paris : Gallimard, 1976. 
PINEAU, Gaston. et MARIE-MICHELE. Produire sa vie : autoformation et autobiographie. Montréal : Éditions Saint-Martin, 1983.

SCHÜTZ, Alfred. Le chercheur et le quotidien. Paris : Klincksieck, [1943]1987.

\section{SOBRE OS ORGANIZADORES:}

\section{Elizeu Clementino de Souza}

Pesquisador 1C CNPq. Professor Titular do Programa de Pós-Graduação em Educação e Contemporaneidade, Universidade do Estado da Bahia (PPGEduC-UNEB). Coordenador do Grupo de Pesquisa (Auto)biografia, Formação e História Oral (GRAFHO/UNEB). Pesquisador associado do Laboratorie EXPERICE (Université de Paris 13-Paris 8). Tesoureiro da Associação Brasileira de Pesquisa (Auto)biográfica (BIOgraph). Diretor Financeiro da ANPEd (2013-2015) Membro do Conselho de Administração da Association Internationale des Histories de Vie en Formation et de Recherche Biographique en Education (ASIHIVIF-RBE). E-mail: esclementino@uol.com.br

iD https://orcid.org/0000-0002-4145-1460

\section{Hervé Breton}

Professor associado em ciências da educação e formação, membro da equipe de Educação, Ética e Investigação em Saúde (EA7505), co-director da revista "Chemins de formation", Presidente da Associação Internacional de Histórias de Vida em Formação (ASIHVIF-RBE). E-mail: herve.breton@univ-tours.fr

(iD https://orcid.org/0000-0003-3536-566X.

\section{Daniel Hugo Suárez}

Doctor en Ciencias de la Educación por la UBA. Profesor Titular Regular de la Facultad de Filosofía y Letras de la UBA. Vicedirector del Instituto en Investigaciones en Ciencias de la Educación. Director de la Revista Argentina de Investigación Narrativa. Coordinador del Área Interdisciplinaria de Formación Docente de la FFYL-UBA. E-mail: danielhugosuarez@gmail.com

(iD) https://orcid.org/0000-0001-6636-5174 